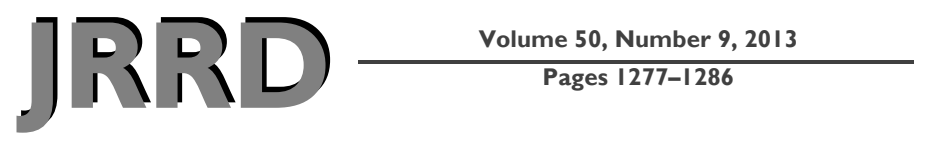

\title{
Circumstances and consequences of falls among people with chronic stroke
}

\author{
Arlene A. Schmid, PhD, OTR; $;^{1-5 *}$ H. Klar Yaggi, MD; ${ }^{6}$ Nicholas Burrus, BA; ${ }^{1}$ Vincent McClain, MD; ${ }^{7}$ Charles \\ Austin, BFA, MDiv; ${ }^{1}$ Jared Ferguson, BS; ${ }^{1}$ Carlos Fragoso, MD; ${ }^{6}$ Jason J. Sico, MD; ${ }^{6}$ Edward J. Miech, EdD; ${ }^{1-2,5}$ \\ Marianne S. Matthias, PhD; ${ }^{1,5,8}$ Linda S. Williams, MD; ${ }^{1-2,4-5,9}$ Dawn M. Bravata, MD ${ }^{1-2,5,9}$ \\ ${ }^{1}$ Health Services Research and Development (HSR\&D) Center of Excellence on Implementing Evidence-Based Prac- \\ tice, Richard L. Roudebush Department of Veterans Affairs (VA) Medical Center, Indianapolis, IN; ${ }^{2}$ VA HSR\&D Stroke \\ Quality Enhancement Research Initiative, Indianapolis, IN; ${ }^{3}$ Department of Occupational Therapy, School of Health \\ and Rehabilitation Sciences, and ${ }^{4}$ Center for Aging Research, Indiana University, Indianapolis, IN; ${ }^{5}$ Regenstrief Insti- \\ tute Inc, Indianapolis, IN; ${ }^{6}$ Yale University School of Medicine, New Haven, CT; ${ }^{7}$ Rushford Center, Middletown, CT; \\ ${ }^{8}$ Department of Communication Studies and ${ }^{9}$ School of Medicine, Indiana University, Indianapolis, IN
}

\begin{abstract}
Falls are common after stroke; however, circumstances and consequences are relatively unknown. Our objectives were to identify the differences between fallers and non-fallers among people with chronic stroke, identify the circumstances of fall events, and examine the consequences of the falls. This is a secondary data analysis; all participants included sustained a stroke. Variables included demographics, stroke characteristics, and comorbidities. Falls were collected via self-report, and circumstances and consequences were derived from participant description of the event and categorized as appropriate. Among 160 participants, 53 (33\%) reported a fall during the 1 yr period. Circumstances of falls were categorized as intrinsic or extrinsic. Location and circumstance of the fall were included: $70 \%$ occurred at home and $40 \%$ were associated with impaired physical or mental state (e.g., inattention to tying shoes). Additionally, $21 \%$ of falls were associated with activities of daily living and mobility and 34\% with slips or trips. The majority who fell sustained an injury (72\%). Injuries ranged from bruising to fractures, and $55 \%$ of those with an injury sought medical care (32\% to emergency department). Poststroke falls are associated with an alarming rate of injury and healthcare utilization. Targeting mental and physical states may be key to fall prevention.
\end{abstract}

Key words: activities of daily living, circumstances, consequences, disability, emergency, falls, injury, mobility, rehabilitation, stroke.

\section{INTRODUCTION}

Falls are a common and serious complication after stroke, with up to 76 percent of people falling poststroke [1-2]. Both the fall risk and associated risk for fall-related injuries persist into the chronic phases of stroke recovery. Moreover, people with stroke who fall have continued increased incidence of serious adverse outcomes, including fractures, depression, and mortality, compared with adults without stroke [3]. People with stroke have a sevenfold increase in the risk of fracture than those without stroke [4]. Additionally, poststroke falls are associated with lowered rehabilitation potential and functional recovery [5] and contribute to poststroke dependence in activities of daily living (ADLs), instrumental ADLs

\footnotetext{
Abbreviations: ADL = activity of daily living, DBP = diastolic blood pressure, DSM = Diagnostic and Statistical Manual of Mental Disorders, GAD = Generalized Anxiety Disorder, IADL = instrumental activity of daily living, $\mathrm{mRS}=$ modified Rankin Scale, NIHSS = National Institutes of Health Stroke Scale, VA = Department of Veterans Affairs.

*Address all correspondence to Arlene A. Schmid, PhD, OTR; Department of Occupational Therapy, Colorado State University, Fort Collins, CO 80523; 970-491-7562. Email: arlene.schmid@colostate.edu http://dx.doi.org/10.1682/JRRD.2012.11.0215
} 
(IADLs), and decreased participation in society [6]. Poststroke falls contribute to the development of fear of falling, ADL limitations, and increased dependence [7].

The circumstances and characteristics of fall events for older adults and nonstroke populations (e.g., people with multiple sclerosis) have been studied [8-10]. However, the literature is limited regarding differences between fallers and non-fallers in the poststroke population, as well as in the circumstances that surround poststroke falls. Hyndman and Ashburn, in a study of 48 poststroke individuals, found that 50 percent of their sample reported a history of a fall since the stroke and that falls were associated with decreased balance and divided attention [11]. In another study, Hyndman et al. found that people with chronic stroke who fell more than once $(n=10)$ had worse mobility, arm function, and ability to complete ADLs, as well as greater anxiety and depression, than those with one or no falls [5]. While it is known that falls are common poststroke [1-2] and fall risk factors are numerous $[5,11]$ a key step in the development of effective interventions to reduce poststroke falls is to identify the circumstances under which people fall after stroke.

The objectives of the study were to (1) identify the differences between fallers and non-fallers among people with chronic stroke, (2) identify the circumstances of fall events, and (3) examine the consequences of the falls.

\section{METHODS}

\section{Design}

Data for the current study were collected as part of a prospective longitudinal randomized trial focused on sleep apnea identification and management among veterans with a history of cerebrovascular disease and hypertension [12]. The methods of the clinical trial have been described elsewhere [12]. As part of this trial, participants were contacted at least every other month for the 1 yr study period to inquire about adverse events. During these in-person or telephone contacts, participants were specifically asked about fall events.

\section{Participants}

Study participants were recruited from two Veterans Health Administration medical centers (West Haven, Connecticut, and Indianapolis, Indiana). Inclusion criteria for the randomized trial included history of stroke or transient ischemic attack and a diagnosis of hypertension or blood pressure $\geq 140 / 90 \mathrm{~mm} \mathrm{Hg}$. Individuals were excluded if they had known sleep apnea, had a sleep disorder other than sleep apnea (e.g., narcolepsy), had a life expectancy less than 6 mo, were unable to wear a nasal or facial continuous positive airway pressure mask, did not speak English, or were unable to provide informed consent. Only individuals with a history of stroke were included in the current analyses.

\section{Measures}

Baseline assessments for all study participants included patient interviews and examinations and medical record reviews.

\section{Demographics}

Demographics include age, sex, education, race, and marital/coupled status.

\section{Stroke and Health Characteristics}

The time since stroke event was collected on the basis of both chart review and patient interview. Strokerelated disability was assessed with the modified Rankin Scale (mRS) [13], a validated measure of the degree of poststroke disability and dependence [14]. The mRS includes six categories of disability that we dichotomously defined as functional independence if the score was $\leq 2$ and moderate to severe disability if the score was $>2$ [15].

Stroke severity was assessed with the National Institutes of Health Stroke Scale (NIHSS) [16]. The NIHSS is valid and reliable, with 11 items that include assessment of consciousness, vision, language, sensory, and motor function. Increasing scores represent greater stroke severity. We examined both the total NIHSS score and individual components possibly related to fall risk (e.g., leg weakness, ataxia).

Comorbidity information was assessed using the Charlson Comorbidity Index [17]. A higher score is indicative of great comorbidity burden. In addition, we included specific variables for diabetes and alcohol use, again given a priori hypotheses regarding their potential association with fall risk. Additional health-related variables include cognition and general pain, assessed with the Saint Louis University Mental Status Examination and the 3-item Brief Pain Inventory, respectively [18]. General health status was assessed with the 12-item Short Form Health Survey [19]. Daytime sleepiness was 
assessed with the Epworth Sleepiness Scale, which has been demonstrated to be reliable and valid [20].

\section{Blood Pressure}

Blood pressure measurements were taken at baseline and at the end of the study by trained research staff both manually and with a $24 \mathrm{~h}$ ambulatory monitor. Sitting blood pressure measurements were taken twice with a sphygmomanometer and stethoscope, using the right arm when possible. Arm and position were noted, and when possible, the same arm and position were used for each measurement for an individual patient. Orthostasis (yes/ no) was also recorded.

\section{Positive and Negative Affect}

Because falls have been associated with mood, anxiety, and depression, we included measures to assess these variables. We included the Positive and Negative Affect Schedule [21], a 20-item scale used to measure stability of affect at this moment, today, and in the recent past. Anxiety was assessed with the 7-item Generalized Anxiety Disorder (GAD) [22]. The seven items are based on Diagnostic and Statistical Manual of Mental Disorders (DSM) criteria for anxiety disorder [23], and it is a brief and reliable measure validated as a screening measure for GAD. Higher scores indicate increased anxiety. The Patient Health Questionnaire was used as a measure of poststroke depression; it is valid and reliable for the stroke population [24]. Items are based on the DSM, with higher scores indicating worse depression symptoms.

\section{Falls}

As described previously, falls were identified and recorded as a part of the routine adverse event collection and reporting protocol. In addition to identification of a fall event, reasons for the fall, location of the fall, and follow-up care were identified through interview questions and chart review. Individuals who sustained at least one fall were considered a "faller" for these analyses. The fall event information was categorized for these analyses to describe both the circumstances and the consequences of falls; the categories were developed explicitly based on the literature $[5,9-10,25]$ and implicitly based on examination of the collected data.

Fall circumstances were separated into intrinsic or extrinsic, personal, and environmental categories, including falls with ADLs (e.g., getting into a car), with movement (e.g., going down stairs), due to trips or slips (e.g., slips due to a wet surface), related to a physical or mental state (e.g., syncope or inattention), location of the event (e.g., at home), and season during which the fall occurred (e.g., winter). These categories are not mutually exclusive. For example, if a person fell while walking down wet stairs, the fall would be classified as a fall with movement (related to the stairs) and due to trips or slips (related to the slippery surface).

Consequences of falls included the occurrence of a fall-related injury, which was further classified according to type of injury (e.g., laceration, fracture) and whether the participant sought or received medical care for the fall-related injury (e.g., emergency department visit).

\section{Data Analyses}

Data were analyzed with SPSS version 19 (IBM Corporation; Armonk, New York). Descriptive statistics (mean \pm standard deviation, frequencies, and proportions, as appropriate) were used for demographic data and stroke and health characteristics. The baseline characteristics of fallers were compared with non-fallers using $t$ tests and chi-square tests. For those who reported a fall, the circumstances and consequences of falls are included as a frequency and percentage. All falls data are based on the first reported fall.

\section{RESULTS}

\section{Falls}

Among the 225 participants in the main trial, 160 (71\%) sustained a stroke and were included in these analyses. This was a chronic stroke population with a mean time from stroke event to study enrollment of $6.8 \pm 8.9 \mathrm{yr}$. Among the individuals with stroke, 53 sustained at least one fall (33\%). Among the 53 individuals who reported a fall, 19 (36\%) reported multiple falls during the 1 yr study period.

Table 1 includes demographic and stroke and health characteristic data for the sample and a comparison between fallers and non-fallers. Fallers were more likely to be white (fallers vs non-fallers: $87 \%$ vs $69 \%, p=$ 0.02 ). They were older (fallers vs non-fallers: $71 \mathrm{vs} 67 \mathrm{yr}$, $p=0.05$ ) and more likely to be married or part of a couple (fallers vs non-fallers: $58 \%$ vs $43 \%, p=0.07$ ), but not significantly different in these variables. Surprisingly, only three stroke and health variables were significantly different between fallers and non-fallers, with fallers 
JRRD, Volume 50, Number 9, 2013

Table 1.

Demographic and stroke characteristics. Data presented as either mean \pm standard deviation or $n$ (\%).

\begin{tabular}{|c|c|c|c|c|}
\hline Variable & $\begin{array}{c}\text { All } \\
(n=160)\end{array}$ & $\begin{array}{c}\text { No Fall } \\
(n=107,67 \%)\end{array}$ & $\begin{array}{c}\text { Fall } \\
(n=53,33 \%)\end{array}$ & $p$-Value \\
\hline \multicolumn{5}{|l|}{ Demographics } \\
\hline Age (yr) & & $67.74 \pm 9.70$ & $71.51 \pm 12.23$ & 0.05 \\
\hline Education (some college) & & $51(47)$ & $23(43)$ & 0.54 \\
\hline Race (white) & $120(75)$ & 74 (69) & $46(87)$ & 0.02 \\
\hline \multicolumn{5}{|l|}{ Stroke and Health Characteristics } \\
\hline Stroke Disability (mRS independent) & $129(81)$ & $92(86)$ & $37(70)$ & 0.02 \\
\hline NIHSS (score) & $2.55 \pm 3.23$ & $3.43 \pm 0.33$ & $2.81 \pm 0.39$ & 0.97 \\
\hline Leg Weakness (yes) & $34(21)$ & $19(18)$ & $15(28)$ & 0.13 \\
\hline Ataxia (any) & & $22(21)$ & $14(27)$ & 0.40 \\
\hline Diabetes (yes) & & $43(40)$ & $28(51)$ & 0.13 \\
\hline Alcohol (any) & $117(74)$ & $78(74)$ & 39 (74) & 0.92 \\
\hline SLUMS Cognition (score) & & $22.24 \pm 5.06$ & $22.58 \pm 5.18$ & 0.69 \\
\hline BPI-3 Chronic Pain (score) & $1.68 \pm 0.48$ & $0.49 \pm 0.05$ & $0.48 \pm 0.06$ & 0.79 \\
\hline SF-12 General Health (score) & & $0.89 \pm 0.87$ & $0.80 \pm 0.11$ & 0.53 \\
\hline SF-12 Physical (score) & $38.41 \pm 9.40$ & $9.75 \pm 0.96$ & $8.85 \pm 1.28$ & 0.46 \\
\hline SF-12 Mental (score) & & $11.42 \pm 1.12$ & $11.51 \pm 1.66$ & 0.79 \\
\hline SBP (mm Hg) & $134.11 \pm 18.66$ & $134.39 \pm 17.47$ & $133.36 \pm 21.03$ & 0.72 \\
\hline DBP (mm Hg) & $73.16 \pm 11.75$ & $74.82 \pm 11.48$ & $69.79 \pm 11.67$ & 0.01 \\
\hline Orthostasis (yes) & 49 (31) & $29(27)$ & $20(38)$ & 0.17 \\
\hline ESS (score) & $7.92 \pm 4.43$ & $7.66 \pm 4.22$ & $8.43 \pm 4.83$ & 0.30 \\
\hline
\end{tabular}

being less independent (mRS of fallers vs non-fallers: $70 \%$ vs $86 \%, p=0.02$ ), having lower diastolic blood pressure (DBP) (fallers vs non-fallers: $69.79 \pm 11.67$ vs $74.82 \pm 11.48 \mathrm{~mm} \mathrm{Hg}, p=0.01$ ), and greater comorbidity (fallers vs non-fallers: $3.06 \pm 2.34$ vs $2.24 \pm 1.98, p=$ $0.03)$. Those who had sustained a fall were more likely to be orthostatic, but there was not a significant difference between groups.

\section{Circumstances of Falls}

Tables 2 and $\mathbf{3}$ describe the circumstances surrounding the reported falls. Circumstances are reported both as a proportion of the number of people who fell as well as a proportion of people who identified the circumstance. For example, falling while doing a chore like gardening was reported by 4 of the 53 (8\%) fallers, and 4 of 11 (36\%) people reported a fall during an ADL. Of individuals who fell, 21 percent reported a fall while completing an ADL such as toileting, gardening, or going out into the community for banking or shopping. Similarly, 21 percent reported a fall with movement, such as while walking, going up or down stairs, or using a ladder. Tripping or slipping was common (34\%), with icy or rainy weather (9\%) being the primary reason. The most common intrinsic circumstance related to a fall was impaired mental or physical state: 40 percent of all falls were related to things like being inattentive to tying shoes, falling asleep and 
Table 2.

Personal and intrinsic circumstances (self-reported) of first identified poststroke fall ( $n=53$ fallers).

\begin{tabular}{|c|c|c|c|}
\hline $\begin{array}{l}\text { Intrinsic or Personal } \\
\text { Circumstances of Falls }\end{array}$ & Descriptive Information ${ }^{*}$ & $\begin{array}{l}\text { Frequency, } \\
\quad n(\%)\end{array}$ & $\begin{array}{c}\text { Within Circumstance, } \\
\text { n (\%) }\end{array}$ \\
\hline Fall With Activity $(n=11$ [21\%] & Household Chores/Gardening & $4 / 53(8)$ & $4 / 11(36)$ \\
\hline \multirow[t]{3}{*}{ fell while completing activity) } & $\begin{array}{l}\text { Community Living/Mobility (going to bank, } \\
\text { grocery store, etc.) }\end{array}$ & $3 / 53(6)$ & $3 / 11(27)$ \\
\hline & Getting In/Out of Car & $2 / 53(4)$ & 2/11 (18) \\
\hline & Activities of Daily Living & 2/53(4) & 2/11 (18) \\
\hline [21\%] fell while moving) & Walking & $3 / 53(6)$ & 3/11 (27) \\
\hline & Ladder/Step Stool & $2 / 53(4)$ & 2/11 (18) \\
\hline & Reaching & $1 / 53(2)$ & $1 / 11(9)$ \\
\hline \multirow{5}{*}{$\begin{array}{l}\text { Fall Due to Trip or Slip ( } n=18 \\
\text { [34\%] fell after trip or slip) }\end{array}$} & Weather (ice/rain) & $5 / 53(9)$ & $5 / 18(27)$ \\
\hline & Slip Out of Bed/Chair & $3 / 53(6)$ & 3/18 (17) \\
\hline & Object in Path & $1 / 53(2)$ & $1 / 18(6)$ \\
\hline & Curb & $1 / 53(2)$ & $1 / 18(6)$ \\
\hline & Cords & $1 / 53(2)$ & $1 / 18(6)$ \\
\hline \multirow{6}{*}{$\begin{array}{l}\text { Fall Related to Mental or Physical } \\
\text { State ( } n=21[40 \%] \text { fell due to } \\
\text { impaired mental or physical state) }\end{array}$} & Balance & $6 / 53(11)$ & $6 / 21(29)$ \\
\hline & Hip/Leg/Knee/Ankle Gave Out & 4/53 (8) & 4/21 (19) \\
\hline & Sleepy/Fell Asleep & $2 / 53(4)$ & 2/21 (10) \\
\hline & $\begin{array}{l}\text { Not Using Assistive Device (forgetting or } \\
\text { not wanting to) }\end{array}$ & $2 / 53(4)$ & $2 / 21(10)$ \\
\hline & Dizzy & $2 / 53(4)$ & 2/21 (10) \\
\hline & Inattentive & $1 / 53(2)$ & $1 / 21(5)$ \\
\hline
\end{tabular}

Table 3.

Environmentally related circumstances (self-reported) of first identified poststroke fall $(n=53)$.

\begin{tabular}{llr}
\hline Environmental Circumstance of Fall & \multicolumn{1}{c}{ Descriptive Information* } & Frequency, $\boldsymbol{n}(\%)$ \\
\hline Home/Away & Home (inside or outside) & $37 / 53(70)$ \\
& Away from Home (inside or outside) & $9 / 53(17)$ \\
& Unknown & $7 / 53(13)$ \\
\hline Location & Inside (home or away) & $27 / 53(51)$ \\
& Outside (home or away) & $17 / 53(32)$ \\
& Unknown & $9 / 53(17)$ \\
\hline Season ${ }^{\dagger}$ & Spring & $13 / 53(25)$ \\
& Summer & $12 / 53(23)$ \\
${ }^{*}$ Each person's fall may be under more than one category. & $14 / 53(26)$ \\
${ }^{\dagger}$ Not weather-specific, i.e., it may snow in spring or fall. & $14 / 53(26)$ \\
\hline \hline
\end{tabular}


falling out of a chair, forgetting to use an assistive device, or using alcohol.

It is not surprising that the environment plays an important role in falling. The majority of falls occurred at home (70\%). Many falls occurred indoors (51\%), but the location varied (i.e., inside home, bank, or hospital). No differences were observed in fall rates across seasons.

\section{Consequences of Falls}

The majority of fallers sustained some degree of injury (72\%) (Table 4). No specific injury was more common than others, but injuries ranged from bruising and sprains and/or strains to fractures. Of the 38 people who sustained an injury, the majority sought medical attention (55\%), including 43 percent who sought care in the emergency department or required hospitalization.

\section{DISCUSSION}

In this chronic stroke population, 33 percent reported a fall during the $1 \mathrm{yr}$ time period. This observed fall incidence was lower than the 76 percent that has been reported in poststroke populations [1-2] but was similar to the 30 percent rate reported for community-dwelling older adult populations [26-27]. This may have been the case because the average time since stroke was close to $7 \mathrm{yr}$ and individuals might have learned to manage some fall-risk factors. A key and unexpected finding was that nearly three-quarters of individuals who fell reported an injury, and over half of these injuries required some level of medical attention. The rate of 55 percent seeking medical attention was much higher than the 20 percent that has been reported in the older adult literature [9-10,25]. These results may indicate that although fall rates may level off over time for people with chronic stroke and may approach rates observed in older communitydwelling populations, the severity of the fall and fallrelated injury may be increased in the poststroke population. These findings provide robust support for the need for further work to develop effective poststroke fall risk prevention programs.

We were surprised that neither stroke severity nor any of the individual components of the neurological examination (such as leg weakness or ataxia) were associated with fall risk. Hyndman et al. found similar results, with no differences in mobility or motor control, between fallers and non-fallers [5]. However, those who fell in this cohort were more likely to have greater disability and more comorbidities, making it likely that the stroke and

Table 4.

Consequences of first identified poststroke fall.

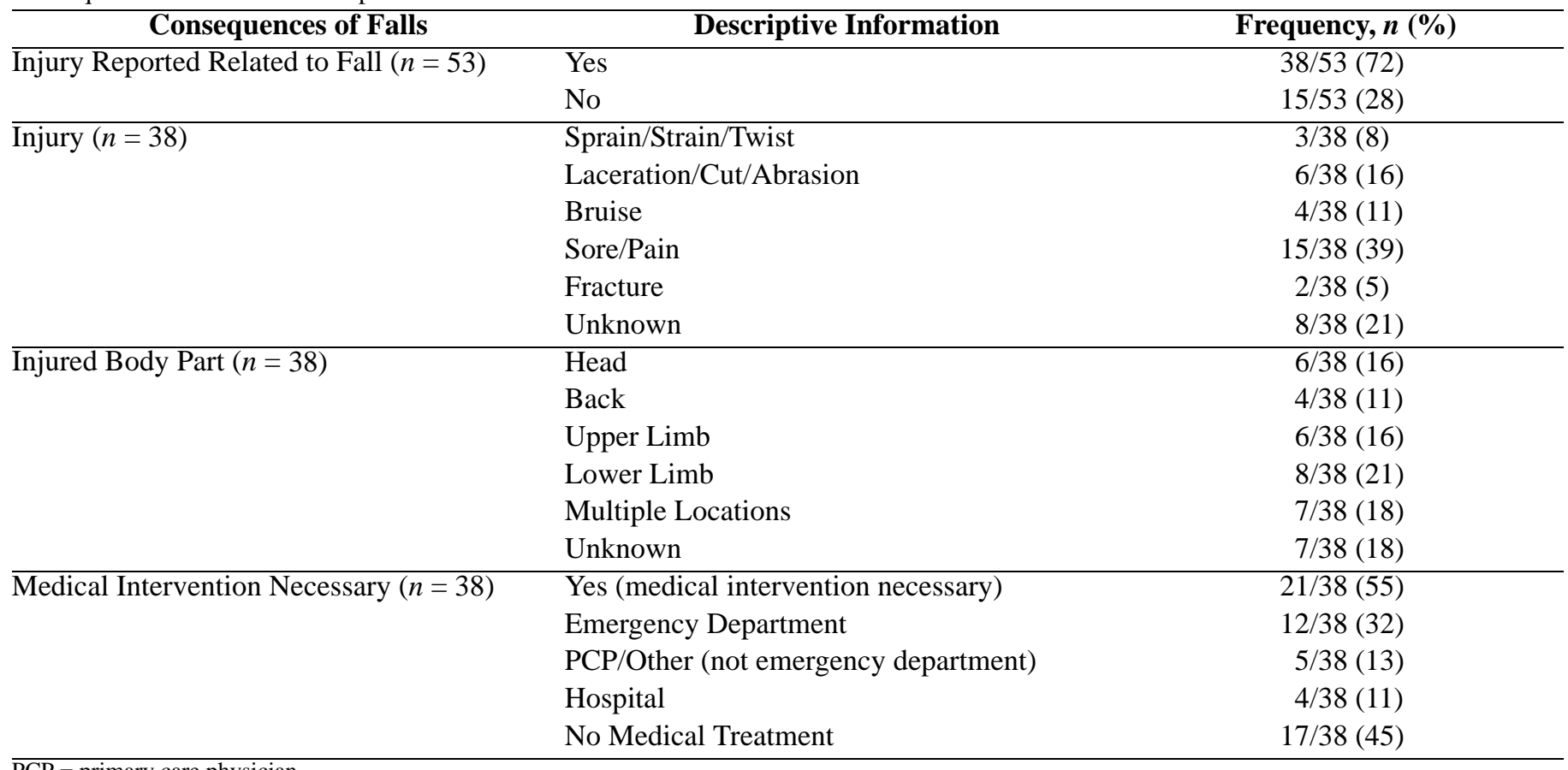


related disability do contribute to falls. It is also of interest that DBP, but not orthostatic hypotension, was associated with fall risk. Our prior work indicates that individuals with stroke and orthostasis are more likely to sustain a fall [28].

This relationship between fall risk and disability is evident when considering the circumstances under which falls occur. We anticipated that falls would most likely occur related to ADLs, such as toileting and showering, or during IADLs, such as doing household chores or community-based activity. Although people did fall with these ADLs, they were more likely to fall due to a trip or a slip. The high frequency of trips and slips, including those related to a crack in the sidewalk, a curb, carpeting, cords, and tree roots, has been reported in the geriatric literature [10,29-30]. In this chronic poststroke cohort, a third of the fallers fell due to a slip or trip, and these events were due to uneven or wet or icy surfaces, cords, curbs, or objects such as a garden gnome. Perhaps these slips and trips are related to visual or sensory impairment, but inattention to detail and surroundings may also be involved.

Very commonly, fallers reported that falls were related to impaired mental or physical states. This includes being inattentive to details like using an assistive device or tying shoes, falling asleep or being sleepy, or drinking too much alcohol. These data support the concept that fall prevention after stroke should not only focus on strength or range of motion but also fall-risk factor modification. Management of fall-risk factors may include enhanced training while using an assistive device but should also include education about the importance of using assistive devices and verbal or tactile cues to remember to take the actual device out of the house. Individuals also identified balance impairment or their legs or knees giving out as contributing factors to fall events; perhaps additional training to transfer to the stronger side or the continuation of balance programming could attenuate fall risk for these individuals with chronic stroke.

\section{LIMITATIONS}

There are limitations to these analyses and results. First, this is an all-veteran sample from two hospitals, the majority of the sample is male and white, and results may not be generalizeable to nonveteran stroke populations. Second, the fall data are based primarily on self-report and not all of the relevant details were known for each fall event. For instance, if someone reported a fall while in Mexico on vacation, we know they were not at home, but do not necessarily know whether or not they were inside or outside. In addition, a participant may forget that a fall was sustained or the details of a fall, although there are no cognitive differences between those who did and did not sustain a fall. Third, although this is a chronic stroke population, the majority were classified as independent according to the mRS. As a group, they may be higher functioning than other poststroke populations, potentially leading to a lower than expected fall rate. Additionally, individuals classified as independent likely engage in different ADLs in more complex environments than those considered dependent. As a result, different fall-risk factors may apply. Finally, we were not able to distinguish between cause and effect of the intrinsic circumstances of the falls; for example, we do not know whether a fall led to ADL restriction and subsequent decreased balance or whether the decreased balance led to the falls.

\section{CONCLUSIONS}

People with chronic stroke commonly sustain a fall and are at great risk for incurring an injury requiring medical attention. When seeking to reduce fall risk, mental and physical states may be more important to address than mobility or strength issues. Issues such as not using an assistive device or forgetting to tie shoes might potentially be addressed through self-management training in addition to more typical balance- and strength-training programs for fall prevention. Self-management interventions focused on poststroke fall risk should be developed and assessed.

\section{ACKNOWLEDGMENTS}

\section{Author Contributions:}

Study concept and design: A. A. Schmid, H. K. Yaggi, V. McClain, C. Fragoso, J. J. Sico, L. S. Williams, D. M. Bravata.

Acquisition of data: N. Burrus, V. McClain, C. Austin, J. Ferguson, C. Fragoso, J. J. Sico.

Analysis and interpretation of data: A. A. Schmid. Drafting of manuscript: A. A. Schmid, D. M. Bravata. Critical revision of manuscript for important intellectual content: A. A. Schmid, H. K. Yaggi, N. Burrus, V. McClain, M. S. Matthias, E. J. Miech, D. M. Bravata.

Statistical analysis: A. A. Schmid, D. M. Bravata.

Obtained funding: D. M. Bravata, H. K. Yaggi, E. J. Miech. 
Administrative, technical, or material support: C. Austin, J. Ferguson, N. Burrus.

Study supervision: D. M. Bravata, H. K. Yaggi.

Financial Disclosures: The authors have declared that no competing interests exist.

Funding/Support: This material was based on work supported by the Department of Veterans Affairs (VA) Health Services Research and Development Service (grant IIR-06-233-2). Dr. Schmid was supported by a Career Development Award from the VA Rehabilitation Research and Development Service (grant CDA D6174W).

Additional Contributions: Dr. Schmid is now with the Department of Occupational Therapy, Colorado State University, Fort Collins, Colorado.

Institutional Review: This study received human subject approvals from the Indiana University Institutional Review Board and the VA Research and Development Committee.

Participant Follow-Up: The authors do not plan to inform participants of the publication of this study.

\section{REFERENCES}

1. Schmid AA, Van Puymbroeck M, Altenburger PA, Miller $\mathrm{KK}$, Combs SA, Page SJ. Balance is associated with quality of life in chronic stroke. Top Stroke Rehabil. 2013; 20(4):340-46. [PMID:23893833]

http://dx.doi.org/10.1310/tsr2004-340

2. Forster A, Young J. Incidence and consequences of falls due to stroke: A systematic inquiry. BMJ. 1995;311(6997): 83-86. [PMID:7613406] http://dx.doi.org/10.1136/bmj.311.6997.83

3. Jørgensen L, Engstad T, Jacobsen BK. Higher incidence of falls in long-term stroke survivors than in population controls: Depressive symptoms predict falls after stroke. Stroke. 2002;33(2):542-47. [PMID:11823667] http://dx.doi.org/10.1161/hs0202.102375

4. Kanis J, Oden A, Johnell O. Acute and long-term increase in fracture risk after hospitalization for stroke. Stroke. 2001;32(3):702-6. [PMID:11239190] http://dx.doi.org/10.1161/01.STR.32.3.702

5. Hyndman D, Ashburn A, Stack E. Fall events among people with stroke living in the community: Circumstances of falls and characteristics of fallers. Arch Phys Med Rehabil. 2002;83(2):165-70. [PMID:11833018] http://dx.doi.org/10.1053/apmr.2002.28030

6. Davenport RJ, Dennis MS, Wellwood I, Warlow CP. Complications after acute stroke. Stroke. 1996;27(3):415-20. [PMID:8610305] http://dx.doi.org/10.1161/01.STR.27.3.415

7. Schmid AA, Rittman M. Consequences of poststroke falls: Activity limitation, increased dependence, and the development of fear of falling. Am J Occup Ther. 2009;63(3):310-16. [PMID:19522139] http://dx.doi.org/10.5014/ajot.63.3.310
8. Nilsagård Y, Denison E, Gunnarsson LG, Boström K. Factors perceived as being related to accidental falls by persons with multiple sclerosis. Disabil Rehabil. 2009;31(16): 1301-10. [PMID:19479575] http://dx.doi.org/10.1080/09638280802532639

9. Campbell AJ, Borrie MJ, Spears GF, Jackson SL, Brown JS, Fitzgerald JL. Circumstances and consequences of falls experienced by a community population 70 years and over during a prospective study. Age Ageing. 1990;19(2):136-41. [PMID:2337010] http://dx.doi.org/10.1093/ageing/19.2.136

10. Berg WP, Alessio HM, Mills EM, Tong C. Circumstances and consequences of falls in independent communitydwelling older adults. Age Ageing. 1997;26(4):261-68. [PMID:9271288] http://dx.doi.org/10.1093/ageing/26.4.261

11. Hyndman D, Ashburn A. People with stroke living in the community: Attention deficits, balance, ADL ability and falls. Disabil Rehabil. 2003;25(15):817-22.

[PMID:12851091] http://dx.doi.org/10.1080/0963828031000122221

12. Bravata DM, Ferguson J, Miech EJ, Agarwal R, McClain V, Austin C, Struve F, Foresman B, Li X, Wang Z, Williams LS, Dallas MI, Couch CD, Sico J, Fragoso C, Matthias MS, Chumbler N, Myers J, Burrus N, Dube A, French DD, Schmid AA, Concato J, Yaggi HK. Diagnosis and treatment of sleep apnea in patients' homes: the rationale and methods of the "GoToSleep" randomized-controlled trial. J Clin Sleep Med. 2012;8(1):27-35. [PMID:22334806] http://dx.doi.org/10.5664/jcsm.1654

13. Wilson JT, Hareendran A, Hendry A, Potter J, Bone I, Muir KW. Reliability of the modified Rankin Scale across multiple raters: Benefits of a structured interview. Stroke. 2005;36(4):777-81. [PMID:15718510] http://dx.doi.org/10.1161/01.STR.0000157596.13234.95

14. Lindley RI, Waddel F, Livingstone M, Sandercock P, Dennis MS, Slattery J, Smith B, Warlow C. Can simple questions assess outcome after stroke. Cerebrovasc Dis. 1994; 4:314-24. http://dx.doi.org/10.1159/000108501

15. Bonita R, Beaglehole R. Recovery of motor function after stroke. Stroke. 1988;19(12):1497-1500. [PMID:3201508] http://dx.doi.org/10.1161/01.STR.19.12.1497

16. Brott T, Adams HP Jr, Olinger CP, Marler JR, Barsan WG, Biller J, Spilker J, Holleran R, Eberle R, Hertzberg V. Measurements of acute cerebral infarction: A clinical examination scale. Stroke. 1989;20(7):864-70. [PMID:2749846] http://dx.doi.org/10.1161/01.STR.20.7.864

17. Charlson ME, Pompei P, Ales KL, MacKenzie CR. A new method of classifying prognostic comorbidity in longitudinal studies: Development and validation. J Chronic Dis. 1987;40(5):373-83. [PMID:3558716] http://dx.doi.org/10.1016/0021-9681(87)90171-8 
18. Krebs EE, Lorenz KA, Bair MJ, Damush TM, Wu J, Sutherland JM, Asch SM, Kroenke K. Development and initial validation of the PEG, a three-item scale assessing pain intensity and interference. J Gen Intern Med. 2009;24(6):733-38. [PMID:19418100] http://dx.doi.org/10.1007/s11606-009-0981-1

19. Müller-Nordhorn J, Roll S, Willich SN. Comparison of the short form (SF)-12 health status instrument with the SF-36 in patients with coronary heart disease. Heart. 2004;90(5): 523-27. [PMID:15084550] http://dx.doi.org/10.1136/hrt.2003.013995

20. Johns MW. Daytime sleepiness, snoring, and obstructive sleep apnea. The Epworth Sleepiness Scale. Chest. 1993; 103(1):30-36. [PMID:8417909] http://dx.doi.org/10.1378/chest.103.1.30

21. Watson D, Clark LA, Tellegen A. Development and validation of brief measures of positive and negative affect: The PANAS scales. J Pers Soc Psychol. 1988;54(6):1063-70. [PMID:3397865] http://dx.doi.org/10.1037/0022-3514.54.6.1063

22. Spitzer RL, Kroenke K, Williams JB, Löwe B. A brief measure for assessing generalized anxiety disorder: The GAD-7. Arch Intern Med. 2006;166(10):1092-97. [PMID:16717171] http://dx.doi.org/10.1001/archinte.166.10.1092

23. American Psychiatric Association. Diagnostic and statistical manual of mental disorders: DSM-IV-TR. 4th ed. Washington (DC): American Psychiatric Association; 2000.

24. Williams LS, Brizendine EJ, Plue L, Bakas T, Tu W, Hendrie H, Kroenke K. Performance of the PHQ-9 as a screening tool for depression after stroke. Stroke. 2005;36(3): 635-38. [PMID:15677576] http://dx.doi.org/10.1161/01.STR.0000155688.18207.33

25. Nachreiner NM, Findorff MJ, Wyman JF, McCarthy TC. Circumstances and consequences of falls in communitydwelling older women. J Womens Health (Larchmt). 2007;16(10):1437-46. [PMID:18062759] http://dx.doi.org/10.1089/jwh.2006.0245

26. Hausdorff JM, Rios DA, Edelberg HK. Gait variability and fall risk in community-living older adults: a 1-year prospec- tive study. Arch Phys Med Rehabil. 2001;82(8):1050-56.

[PMID:11494184]

http://dx.doi.org/10.1053/apmr.2001.24893

27. Tinetti ME. Clinical practice. Preventing falls in elderly persons. N Engl J Med. 2003;348(1):42-49.

[PMID:12510042]

http://dx.doi.org/10.1056/NEJMcp020719

28. Phipps MS, Schmid AA, Kapoor JR, Peixoto AJ, Williams LS, Bravata DM. Orthostatic hypotension among outpatients with ischemic stroke. J Neurol Sci. 2012;314(12):62-65. [PMID:22099880] http://dx.doi.org/10.1016/j.jns.2011.10.031

29. Campbell AJ, Borrie MJ, Spears GF. Risk factors for falls in a community-based prospective study of people 70 years and older. J Gerontol. 1989;44(4):M112-17.

[PMID:2738307] http://dx.doi.org/10.1093/geronj/44.4.M112

30. Campbell AJ, Reinken J, Allan BC, Martinez GS. Falls in old age: A study of frequency and related clinical factors. Age Ageing. 1981;10(4):264-70. [PMID:7337066] http://dx.doi.org/10.1093/ageing/10.4.264

Submitted for publication November 26, 2012. Accepted in revised form May 2, 2013.

This article and any supplementary material should be cited as follows:

Schmid AA, Yaggi HK, Burrus N, McClain V, Austin C, Ferguson J, Fragoso C, Sico JJ, Miech EJ, Matthias MS, Williams LS, Bravata DM. Circumstances and consequences of falls among people with chronic stroke. J Rehabil Res Dev. 2013;50(9):1277-86.

http://dx.doi.org/10.1682/JRRD.2012.11.0215

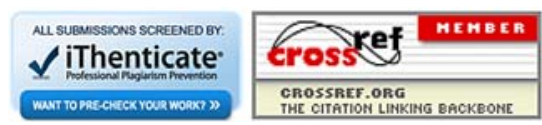


